\title{
CARTOGRAFIA DA ILUSTRAÇÃO CIENTÍFICA NO BRASIL
}

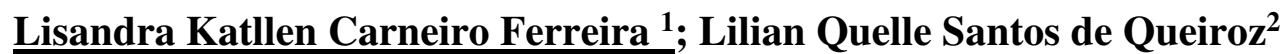

1. Bolsista PIBIC/CNPq, Graduando em Engenharia Civil, Universidade Estadual de Feira de Santana, Participante do projeto de Pesquisa Estudos sobre Desenho, Ciência e Produção do Conhecimento, Universidade Estadual de Feira de Santana, e-mail: liskatllen@gmail.com

2. Orientador, Departamento de Letras e Artes, Universidade Estadual de Feira de Santana, líder do Grupo de Pesquisa Estudos sobre Desenho, Ciência e Produção do Conhecimento dgp.cnpq.br/dgp/espelhogrupo/8457034722443852

E-mail: lilian@uefs.br

PALAVRAS-CHAVE: Ilustração Científica; Cartografia; Produção do conhecimento.

\section{INTRODUÇÃO}

O ser humano usa o desenho desde os primórdios da humanidade para se expressar, registrar e ensinar. Os primeiros desenhos que se tem conhecimento são as pinturas feitas em rochas, chamadas de pinturas rupestres. São registros dos costumes e das práticas cotidianas do homem do Paleolítico.

Séculos depois, percebendo a necessidade de se guardar o que se conhecia, filósofos e naturalistas passaram a desenhar animais em seu habitat natural, plantas, cotidiano da sociedade, escrever sobre materiais e técnicas de desenho, o que contribui para o avanço nos estudos de determinadas áreas, como astrologia, geografia, Antropologia, zoologia, etc.

É com o Renascimento no fim do século XIV que a Europa volta à valorização do homem (humanismo), da razão (racionalismo) e do naturalismo da Antiguidade Clássica, abandonados anteriormente na Idade Média. As navegações aumentaram no período renascentista, e a fim de novos mercados e rotas comerciais, a expansão marítima avançou para além do atlântico. Sentiu-se a necessidade de guardar/ registrar o conhecimento adquirido até o período, então a nobreza europeia e o clero financiavam as enciclopédias. Elas continham ilustrações do Novo Mundo, novas plantas e animais, criou-se uma catalogação das novas descobertas. Na área cartográfica, o desenho dos mapas foi essencial para a demarcação dos territórios, já que, as novas conquistas tornaram difíceis a identificação dos limites territoriais apenas visualmente.

Ao se pensar sobre Ilustração Científica no Brasil, faz-se necessário discorrer sobre o desenho, o ato de desenhar, suas relevâncias, capacidade de expressão artística do ser humano, bem como a capacidade de representação do pensamento. Nesta perspectiva, desenhar é a arte que explora sua imaginação e sua capacidade de expressar aquilo que se pensou; é hobbie, é profissão, é explicação, é entendimento e escrita; é guardar memórias.

O desenho institui-se como um espaço privilegiado de investigação, no desemaranhar dos fios do pensamento, em que, desenhar é como clarificar os passos, percursos e estratégias da nossa consciência, trazendo-os à superfície do suporte. (BISMARCK, 2000, p.01)

Ou seja, o desenho traz à tona o que nossa consciência gostaria de materializar. É uma forma de desembaralhar os muitos pensamentos que passam pela mente do ser humano, seja o desenho compreensível a outro ou apenas à própria pessoa. 
O desenho está presente em toda a vida de um ser humano, seja ele o desenhista ou não. Nesse estudo buscou-se mapear os espaços onde o desenho cientifico, sob a forma de ilustração tem espaço e é praticado não apenas como instrumento técnico de representação, mais também como espaço de pesquisa e divulgação da multiplicidade que o desenho e sua prática podem alcançar.

\section{MATERIAL E MÉTODOS OU METODOLOGIA}

A pesquisa teve início com um levantamento bibliográfico, partindo do acervo do Projeto de pesquisa Desenho e Ciência: Contribuições, metodologias e técnicas e foi ampliando para os espaços de discussão do tema como anais de eventos científicos, artigos, contato com os núcleos localizados, ilustradores e pesquisadores da temática. Ainda como metodologia de pesquisa utilizamos a cartografia no conceito estabelecido por Gilles Deleuze e Félix Guattari (1995), que entende esse aspecto como

um processo, e não representar um objeto. A cartografia atribuída como método, cria seus próprios movimentos, seus próprios desvios. É um projeto que pede passagem, que fala, que incorpora sentimentos, que emociona. É um mapa do presente que demarca um conjunto de fragmentos, em eterno movimento de produção. (MOURA; HERNANDEZ, 2009, p.22)

Nesse aspecto, a pesquisa buscou construir um mapa acerca do movimento realizado pelos centros de práticas de Ilustração Científica no País, pertencentes ou não a Universidades ou instituições, demonstrando nesse sentido uma preocupação para além da descrição destes Centros e sim como se organizam e podem dialogar com outros espaços de comum interesse.

\section{RESULTADOS E/OU DISCUSSÃO}

O objetivo deste estudo é investigar a difusão da ilustração científica no Brasil, ou seja, mostrar locais que ensinam ou promovem a ilustração científica de alguma forma. Foi tomado como base a pesquisa da ilustradora Fátima Zagonel, Núcleos de Formação de Ilustradores no Brasil (2016), apresentado no V Encontro Brasileiro sobre Ilustração Científica em uma mesa redonda.

Nesse trabalho, ela cita núcleos, centros e associações que promovem cursos, minicursos, oficinas, disciplinas em universidades, dentre outros. Iniciando o mapeamento pelo Núcleo de Ilustração Científica da Universidade de Brasília (NICBio), localizado em Brasília, Distrito Federal. Esse núcleo é coordenado pelo doutor e professor Marcos Antonio S. Silva Ferraz, que segundo Gabriela Hirata ${ }^{1}$, foi quem fez o projeto do núcleo e apresentou ao Conselho do Instituto de Biologia, cuja aprovação veio na $79^{a}$ reunião em 23 de abril de 1999. Não houve financiamento e o vínculo do núcleo é com o Instituto de Biologia da Universidade. Além do professor e coordenador Marcos e a estagiária Gabriela, o núcleo possui mais dois estagiários e alunos, Pedro Henrique Oliveira e Nicolau Rocha de Souza. Segundo Zagonel (2016), o NICBIO oferece cursos de extensões e as seguintes disciplinas optativas tanto para a graduação quanto para a pós-graduação. Na graduação, tem-se: Ilustração Científica, Técnicas Avançadas em Ilustração Científica, Ilustração Científica aplicada à Prática de Campo, Tópicos em Ilustração Científica e Estágio em Ilustração Científica, essas

\footnotetext{
${ }^{1}$ Gabriela Hirata, aluna do curso de biologia da Unb, estagiária do NicBio, forneceu informações para a minha pesquisa. Contato: gabrielahirata94@gmail.com.
} 
disciplinas são abertas a todos os cursos da graduação. Na pós-graduação, tem-se a disciplina Introdução à Ilustração Científica, ministrada para o Programa de PósGraduação em Ecologia. Mais informações sobre o núcleo no site www.nicbio.unb.br . No estado de Minas Gerais, tem-se o Núcleo de Ilustração Científica (NIC) na Universidade Federal de Lavras (UFLA), na cidade de Lavras, que, de acordo com Zagonel (2016), é um núcleo de estudos em ilustração científica, o qual, algumas pessoas se reúnem semanalmente para compartilhar conhecimentos, praticar exercícios, a fim de melhorar as técnicas de ilustração em diversas áreas, como botânica, zoologia, anatomia e paleontologia. A UFLA ainda apresenta uma disciplina de Ilustração Entomológica, na pós-graduação em Entomologia.

No estado de São Paulo, encontra-se o Núcleo de Ilustração Científica (NIC-IB) ${ }^{2}$ da Universidade de São Paulo (USP), vinculado ao Instituto de Biociências. É um grupo formado por alunos da graduação e pós-graduação da USP, que buscam compartilhar informações e divulgar a ilustração científica. Não oferecem cursos, nem aulas aos membros participantes, mas procuram divulgar eventuais cursos oferecidos por ilustradores anônimos da região. O núcleo realiza atividades de extensão, como palestras, ilustrações sem fins lucrativos afins de complementar material didático da graduação, visitas ao jardim botânico, oficinas de desenho, entre outros. Segundo Zagonel (2016), o grupo diminuiu suas atividades, por conta da saída de alguns fundadores, após os mesmos concluírem suas graduações. Botânica Arte e Companhia é um grupo autônomo da cidade de São Paulo que, de acordo com Zagonel (2016), oferece cursos livres de ilustração botânica com Iroe Sasaki, Carmen Fidalgo e Cecília Tomasi que também ministra cursos livres no Inst. de Botânica.

No Rio de Janeiro, existe a Escola Nacional de Botânica Tropical, as aulas do Programa de Ilustração Botânica ocorrem no Jardim Botânico desde de 2001 e são ministradas por Paulo Ormindo e Malena Barreto. O conteúdo dessas aulas são Introdução à Ilustração Botânica, Desenho Botânico, Ilustração Botânica em aquarela e técnica de grafite e bico de pena, de acordo com Zagonel (2016). Em Maricá, Rio de Janeiro, existe o Projeto Boas Mãos que ensinam crianças e jovens de algumas escolas municipais de Maricá sobre Ilustração Botânica e Entomológica, as aulas são ministradas por Carolina Siqueira Ferreira.

No Sul, a pesquisa de Zagonel (2016) detectou o Centro de Ilustração Botânica do Paraná (CIBP), em Curitiba e Nacasa Coletivo Artístico, em Florianópolis, estado de Santa Catarina. O primeiro é uma entidade socioeducativa sem fins lucrativos que tem 15 sócios e 6 ministram cursos livres de Ilustração Botânica com duração de 8 meses, abordando técnicas precisas de grafite, aquarela e bico de pena, além disso, promovem a Ilustração Botânica por meio de exposições e publicações de calendários e livros. O Nacasa é um coletivo de artistas, pesquisadores e web designers que usam a casa como ateliê e espaço de trabalho individual, assim como promovem cursos de ilustração científica e de arte, e exposições temporárias.

No Nordeste, encontra-se na Bahia duas universidades que oferecem disciplinas optativas envolvendo ilustração científica. Na Universidade Estadual de Feira de Santana, existe uma disciplina optativa ofertada para os cursos de Bacharelado e

\footnotetext{
${ }^{2}$ Site do núcleo: http://www.ib.usp.br/nic/?page_id=17 Acesso: 27/07/2017
} 
Licenciatura em Biologia, o nome é Percepção Morfológica e consiste em percepção visual e representação gráfica de formas orgânicas: animadas e inanimadas, dando-se ênfase à biomorfologia e a mineromorfologia. Estrutura das formas orgânicas e aparência natural: forma, volume, proporção, cor, textura, simetria, ramificação, rugosidade, transparência e porosidade. Métodos de registro e técnicas (nanquim e aquarela). Possui carga horária de 60 horas e é ministrada pelos professores Ivoneide Costa, Antonio Wilson de Souza e Robson Santana.

Na Universidade Federal do Recôncavo Baiano, campus de Cruz das Almas, a disciplina ofertada é a Ilustração Científica que é ministrada por Marcio Lacerda Lopes Martins, para o curso de Bacharelado e Licenciatura de Biologia e eventualmente com participação de estudantes de Engenharia de Pesca e Agronomia. A ementa consiste na história da ilustração científica no Brasil e no mundo e apresenta as principais técnicas para os alunos, como grafite e nanquim.

\section{CONSIDERAÇÕES FINAIS}

A pesquisa objetivou mapear, cartografar espaços onde a ilustração cientifica é praticada. Percebeu-se que ainda há grande dificuldade em conseguir informações sobre esses locais, pois além de existir poucos no Brasil, o acesso a tais informações também é difícil. Porém foi estabelecido contato com alguns ilustradores que contribuíram para essa pesquisa, tais como: Fátima Zagonel e Márcio Lacerda Lopes Martins.

No Brasil, a Ilustração se iniciou com a vinda dos portugueses, fazendo os primeiros relatos das espécies nativas. Mas foi com os holandeses, que a ilustração intensificou passando a catalogar tais espécies. Carneiro (2011) afirma que a botânica foi a primeira área científica a se desenvolver de fato no país, devido à criação do Jardim Botânico. Diversas expedições estrangeiras existiram no país, sempre à procura de novas espécies, novas ilustrações. Os brasileiros tomavam conhecimento tardiamente sobre tais obras produzidas. Foi com João Barbosa Rodrigues (1842-1909) que houve trabalhos originalmente brasileiros. A partir daí a ilustração científica no Brasil foi se desenvolvendo. Hoje, essa área é muito explorada, porém pouco reconhecida.

\section{REFERÊNCIAS}

PEREIRA, ROSA MARIA ALVES. 2007. ABCDesenho. Belo Horizonte, MG. PROEX/UFMG. 12 p.

MOURA, CARLA BORIN; HERNANDEZ, ADRIANE. Cartografia como método de pesquisa em Arte. Centro de Artes/UFPel. Vll1 ${ }^{\circ}$ Seminário História da Arte.UFPel. Pelotas, 2009.

CARNEIRO, DIANA. 2011. Ilustração botânica: princípios e métodos. 22 ed. Curitiba, PR. Editora UFPR. 232 p.

DELEUZE, GILLES; GUATTARI, FÉLIX. Mil platôs - Capitalismo e esquizofrenia. São Paulo, SP, Editora 34. 1995.

BISMARCK, MARIO. 2000. Desenhar é o desenho. [online] Homepage: https://repositorio-aberto.up.pt/handle/10216/19089

ZAGONEL, FÁTIMA. 2016. Núcleos de formação de ilustradores no Brasil. Contato: fatima@zagonel.net 